\title{
As disputas sino-vietnamitas no Mar do Sul: desafios para além da questão regional $^{1}$
}

\section{The sino-vietnamite disputes in the South Sea: challenges beyond the regional issue}

DOI: $10.21530 /$ ci.v12n3.2017.679

\author{
Diego Pautasso ${ }^{2}$ \\ Alexandre Cesar Cunha Leite ${ }^{3}$ \\ Gaio Doria ${ }^{4}$
}

\section{Resumo}

O presente artigo tem por objetivo analisar a situação atual das relações entre a China e o Vietnã na questão relativa às disputas territoriais no Mar do Sul da China. Por um lado, China e Vietnã convergem em seus regimes políticos e modelos econômicos, além de participar de processos de integração regional conjuntos. Por outro, possuem interesses políticos e territoriais divergentes sobre espaços no Mar do Sul da China, região estratégica nos âmbitos comercial e geopolítico. Trata-se de um dos litígios territoriais mais importantes envolvendo os países da região e seus potenciais aliados, com destaque para a forte penetração dos Estados Unidos (EUA). É, pois, um tema complexo que engloba questões militares, econômicas e diplomáticas, com desdobramentos para o sistema internacional. O argumento proposto é que esse litígio tende a determinar não apenas a evolução das relações bilaterais sino-vietnamitas, mas a dinâmica de integração regional e, sobretudo, a projeção de poder dos Estados Unidos em uma porção chave do mundo oriental.

Palavras-chave: China, Vietnã, Mar do Sul da China, Disputas Territoriais.

\footnotetext{
Abstract

The purpose of this article is to analyze how relations between China and Vietnam derive from territorial disputes in the South China Sea. On the one hand, China and Vietnam have convergent political regimes and economic models, and participate in joint regional integration

1 Os autores agradecem os comentários e sugestões dos pareceristas anônimos. Como de praxe, todas as informações e opiniões contidas no artigo são, exclusivamente, de responsabilidade dos autores.

2 Departamento de Relações Internacionais da Universidade do Vale do Rio Sinos (UNISINOS), São Leopoldo/RS, Brasil. E-mail: dgpautasso@gmail.com

3 Programa de Pós-Graduação em Relações Internacionais da Universidade Estadual da Paraíba (UEPB) e Programa de Pós-Graduação em Gestão Pública e Cooperação Internacional da Universidade Federal da Paraíba (UFPB), João Pessoas/Paraíba, Brasil. E-mail: alexccleite@gmail.com.

4 Universidade do Povo da China em Beijing, China. E-mail: gaiodoria@gmail.com

Artigo submetido em 31/05/2017 e aprovado em 24/08/2017.
} 
processes. On the other hand, they have divergent political and territorial interests over spaces in the South China Sea, a strategic region in the commercial and geopolitical spheres. This is one of the most important territorial disputes, involving the countries of the region and their potential allies, especially the strong penetration of the United States. Is therefore a complex subject that encompasses military, economic, and diplomatic issues, with consequences for the international system? The argument is that this litigation tends to determine not only the evolution of Sino-Vietnamese bilateral relations, but the dynamics of regional integration and, above all, the projection of US power into a key portion of the oriental world.

Keywords: China, Vietnam, South China Sea, Territorial Disputes.

\section{Introdução}

As relações entre China e Vietnã têm sido marcadas por dinâmicas convergentes e divergentes. São países que preservam regimes políticos liderados por partidos comunistas e, não obstante, os debates acerca da natureza de seus modelos econômicos, são autodefinidos por seus próprios governos como formas de socialismo onde há o mecanismo de mercado. O partido comunista do Vietnã define o atual sistema econômico como uma economia de mercado de orientação socialista, enquanto o partido comunista da China prefere o termo socialismo de mercado.

Apesar dessa identidade política, as disputas no Mar do Sul da China têm fortalecido as rivalidades bilaterais, entre o grupo de países da região costeira; redefinindo o padrão de alianças e relações na região. Trata-se, como se pode observar pelos números que seguem, de uma região estratégica: i) reservas de 11 bilhões de barris de óleo e 190 trilhões de metros cúbicos de gás natural; ii) rota marítima de extrema importância, por onde passam cerca de U\$5,3 trilhões de dólares do total anual de comércio do mundo e onde estão metade dos 50 maiores portos do mundo5; e iii) alto potencial de exploração dos demais recursos naturais do mar. É uma das regiões com maior potencial de escalada de violência, pois os litígios territoriais sino-vietnamitas e a penetração da grande potência hegemônica, os Estados Unidos, doravante EUA, tornam o equilíbrio de forças muito mais delicado (BUSZYNSKI, 2012).

A compreensão dessa temática ganha complexidade visto que os estudos de segurança possuem fraquezas e pontos cegos, frutos de um viés anglocêntrico

5 Ver detalhes no site da World Shipping disponível em: http://www.worldshipping.org/about-the-industry/ global-trade/top-50-world-container-ports 
(BUZAN; HANSEN, 2012), mas também dada a existência de novas abordagens que dão conta da cosmologia oriental. Cabe lembrar que no sistema sinocêntrico asiático não havia noções de soberania e igualdade jurídica entre as nações; também não havia excepcionalismo universalista nem ambições territoriais ao estilo estadunidense (KANG, 2003). De maneira arguta, Kissinger (2011, p. 40-42) compara o jogo chinês wei qi com o xadrez e Sun Wu com Clausewitz para ilustrar as diferentes formas de pensar e agir. Logo, percebe-se que o tema é complexo não somente pela quantidade de atores dispersos no tabuleiro regional e pelo número de disputas em jogo, mas por requerer parcimônia para lidar com essas heranças culturais e políticas tradicionais como novas acomodações oriundas de lógicas modernas, entendidas como os Estados nacionais e a economia de mercado capitalista.

Para a China, está posto o objetivo de evitar a política estadunidense voltada a fomentar as tensões para legitimar sua presença e, quiçá, usar uma eventual escalada belicosa como forma de conter a ascensão chinesa. A obsessão chinesa tem sido o desenvolvimento nacional que, por sua vez, depende da preservação da estabilidade regional e mesmo global. Em outras palavras, o entrelaçamento entre desenvolvimento e segurança está claro para o governo chinês; e, por isso, todas as provocações serão meticulosamente calculadas. O Vietnã, por sua vez, não desconhece a centralidade da China, mas busca estreitar relações com os EUA para equilibrar as negociações e garantir certa estabilidade na região.

Para compreender tal problemática, o artigo busca analisar, primeiramente, a política externa chinesa e sua projeção regional. Segundo, aborda-se o papel do Vietnã, em suas relações tensas e contraditórias com a China e os EUA. Por fim, o objetivo é compreender como os EUA buscam explorar as rivalidades sinovietnamitas para projetar poder na região a partir dos conflitos territoriais no Mar do Sul da China.

\section{Ascensão chinesa e o entorno regional}

As reformas econômicas e políticas implementas pela China comunista na década de 1970 alçaram o país ao patamar de segunda maior economia do mundo no início do século XXI e à maior, quando medida em paridade de poder de compra em 2015, com 19,8 trilhões de dólares contra 18 trilhões dos EUA6 ${ }^{6}$.

6 Ver dados oficiais do Banco Mundial: http://data.worldbank.org/data-catalog/GDP-PPP-based-table 
As novas capacidades econômicas, política e militares do gigante asiático alteraram sua posição na ordem internacional vigente e as configurações de poder no mundo. É notório que o potencial militar chinês vem crescendo quase que proporcionalmente ao seu desempenho econômico, fortalecendo seu engajamento em assuntos de segurança, na dinâmica de integração econômica da Ásia e nos investimentos na África e na América Latina, na criação de instituições alternativas ao sistema financeiro vigente, entre outras iniciativas. Inegavelmente, a ascensão da China aparece no horizonte como um claro desafio à ordem internacional atualmente liderada pelos EUA - embora a China ainda esteja em uma fase onde busca primeiramente diminuir o atraso tecnológico em face da grande potência hegemônica.

Com o intuito de se contrapor a essa visão, oficiais do governo e acadêmicos chineses formularam a ideia de desenvolvimento pacífico e da construção de um mundo harmonioso (和平发展与构建和谐世界), conceito apresentado ainda em 2005 por Hu Jintao e depois consolidado no $17^{\circ}$ Congresso do Partido Comunista da China (2007). E, desde meados de 2005, a China concentrou-se em introduzir o conceito de harmonia (和谐) na sua política externa. Esse é um dos pilares fundamentais do pensamento confuciano no tocante à governança. A ideia, no entanto, foi inserida no arcabouço teórico do partido comunista da China oficialmente durante o governo do presidente Hu Jintao. Esse apontava a necessidade de uma "sociedade harmoniosa" como um objetivo para o futuro do desenvolvimento socioeconômico da China. Em setembro de 2005, Hu conclamou a necessidade de um "mundo harmonioso" em seu discurso no encontro em homenagem ao $60^{\circ}$ aniversário da fundação das Nações Unidas 7 . Logo em seguida, ainda no mesmo ano, o governo chinês publicou um documento intitulado “O caminho para o desenvolvimento pacífico da China” (中国和平发展道路), onde expõe o papel positivo do crescimento chinês na busca pelo ideal nobre da paz e do desenvolvimento da humanidade como um todo (Xinhuanet, 2005).

O novo conceito de segurança (新安全观) tem buscado integrar as questões securitárias às concepções históricas chinesas, avessas ao emprego da força como recurso prioritário. Conforme o documento publicado pelo Ministério das Relações Exteriores, "na visão da China, o cerne deste novo conceito de segurança deve incluir confiança mútua, benefício mútuo, igualdade e coordenação” (MINISTRY OF FOREIGN AFFAIRS OF THE PEOPLE'S REPUBLIC OF CHINA, 2012). Como

7 Ver http://www.un.org/webcast/summit2005/statements15/china050915eng.pdf 
destaca Gill (2007), a política chinesa dedica atenção aos mecanismos de segurança regional e à defesa da soberania face intervenções estrangeiras - justamente o que atravessa os litígios no Mar do Sul da China.

No bojo desse debate, um proeminente membro do partido comunista da China, Zheng Bijian, cunhou, em 2003, o conceito de "ascensão pacífica" da China (中国和平崛起), ao dizer que “a única opção da China é se esforçar para ascender e, mais importante, para lutar por uma ascensão pacífica” (ZHENG, 2005, p. 14-19). Esse conceito gerou controvérsias na elite dirigente chinesa. Alguns nacionalistas o acharam equivocado, pois sinalizava que um eventual movimento independentista (Taiwan ou Tibete) ou disputa territorial seria tolerada. Outros pensavam que o conceito provocava desconfiança nos vizinhos por reafirmar a ideia de "ascensão". A controvérsia em torno do termo ascensão empurrou a liderança chinesa a trocar as palavras, mas mantendo a ideia principal. Em 2004, no Fórum Boao, o então presidente Hu Jintao usou o desenvolvimento pacífico da China (中国和平发展) como substituto. Desde então, esse tem sido o jargão mais utilizado nos documentos oficiais. ${ }^{8}$

O fato é que tem ocorrido atualizações nos conceitos de política externa ao longo das quatro últimas gerações de liderança coletiva do PCCh. É inegável, contudo, que os Cinco Princípios de Coexistência Pacífica - nomeadamente, respeito mútuo a integridade territorial e soberania; não agressão mútua; não interferência nos assuntos internos; igualdade; benefício mútuo e coexistência pacífica - foram concebidos pela China para resolver a questão da convivência com países não socialistas e para equacionar questões pendentes do ponto de vista histórico (LI, 2012). Inicialmente proposta por Zhou Enlai para reduzir a tensão existente derivada da questão entre a China e a Índia no tocante ao Tibete, passou do âmbito das relações bilaterais para a esfera internacional através da Conferência Afro-Asiática realizada em Bandung, na Indonésia em 1955. Essa foi a base da Conferência de Bandung, cujo mote se resumiu a dez pontos sobre "a promoção da paz e cooperação mundiais", e de outros mecanismos multilaterais como o Movimento dos Não Alinhados e o G-77. Representou, sem dúvida, uma nova etapa na história mundial, sendo a origem das relações Sul-Sul e sua organização em torno de princípios, valores e ideias comuns (PEREIRA; MEDEIROS, 2015).

Além disso, o binômio paz e desenvolvimento não é original da terceira geração da liderança do PCCh. Deng Xiaoping, em 1985, já problematizava a

8 Ver http://english.boaoforum.org/document2004/11119.jhtml 
questão da interpretação da ascensão chinesa, utilizando conceitos que iriam se tornar chave no discurso chinês nas décadas seguintes, tais como relação Sul-Sul, “anti-hegemonismo", dentre outros. Deng é categórico ao afirmar que "quando a hora chegar, a China certamente irá desempenhar um grande papel na manutenção da paz e estabilidade mundial” (DENG, 1994, p. 110-112).

É com os desdobramentos históricos e político-diplomáticos, com as intrínsecas contradições e conflitos de interesses e direitos, que se poderá captar a verdadeira natureza da ascensão chinesa. Nesse sentido, a questão do Mar do Sul assume uma importância singular. O número de países que clamam soberania sobre a região, a partilha das reservas de recursos naturais e a complexidade em acomodar as diversas disputas serão um grande desafio para a resolução do imbróglio. E, naturalmente, o envolvimento da superpotência estadunidense recrudesce a complexidade da questão. Dessa forma, a consolidação da China como líder regional e potência mundial passa por saber conduzir tais litígios - que, por extensão, são essenciais para sua integridade territorial, segurança energética, integração regional e comércio exterior.

As disputas no Mar do Sul envolvem diversas ilhas e zonas econômicas exclusivas (mar territorial) entre diversos países da região, nomeadamente a República Popular da China, a República da China (Taiwan), Filipinas, Vietnã, Brunei e Malásia. A República Popular da China possui as maiores aspirações em termos territoriais - almeja uma área definida através do conceito de "linha de nove-traços” (九段线) (originalmente, “linha dos onze-traços”), proposta pela República da China durante o governo do Guomindang, com ajuda técnica dos EUA, antes da derrota para os comunistas, em 1947, com intuito de reivindicar soberania sob as ilhas Paracels, Prats e Spratly, logo após a rendição japonesa na Segunda Guerra (FRAVEL, 2011).

O imbróglio aumentou quando o Tratado de São Francisco (1951), que dispôs sobre a situação do Japão no pós-guerra, não resolveu a questão das ilhas, deixando a República Popular da China (RPC) e a República da China (Taiwan) de fora de qualquer negociação. Os comunistas emitiram notas de repúdio e, posteriormente, o premier Zhou Enlai subtraiu dois traços, retirando o Golfo de Tonkin e formando a "linha de nove-traços", que a China reivindica atualmente.

Segundo a entrevista concedida ao Consensus Net por Xue Li (LI, 2016), chefe da Divisão Estratégica Internacional do Instituto de Economia e Política Mundial da Academia de Ciências Sociais da China, não existe consenso entre os acadêmicos chineses sobre o assunto. Há, todavia, quatro grandes interpretações 
sobre o significado da "linha dos nove-traços": demarcação de fronteiras marítimas, soberania sobre as ilhas, direitos históricos e águas históricas.

O governo chinês adota como posição oficial os direitos históricos sobre a região, pois argumenta que as atividades dos chineses no Mar do Sul da China datam de mais de dois mil anos. A China teria sido a primeira a descobrir, nomear e se dedicar à exploração e ao aproveitamento das ilhas localizadas no Mar do Sul, além de ter sido a primeira a exercer soberania e jurisdição sobre elas de forma contínua, pacífica e eficaz. Segundo o recente Livro Branco, publicado pelo Gabinete de Imprensa do Conselho de Estado da China envolvendo a questão, há numerosos documentos históricos para comprar essa afirmação, tais como o "Yi Wu Zhi (Relato de Coisas Estranhas) da dinastia Han do Leste (25-220); Fu Nan Zhuan (Registro de Fu Nan) do Período dos Três Reinos (220-280); Meng Liang Lu (Registro de um Sonhador Acordado) e Ling Wai Dai Da (Notas sobre as Ilhas além das Passagens) da dinastia Song (960-1279); Dao Yi Zhi Lüe (Breve Relato das Ilhas) da dinastia Yuan (1271-1368); Dong Xi Yang Kao (Estudos sobre Oceanos do Leste e do Oeste) e Shun Feng Xiang Song (Bom Vento para Escolta) da dinastia Ming (1368-1644); assim como Zhi Nan Zheng Fa (Navegações com Bússola) e Hai Guo Wen Jian Lu (Registros de Coisas Vistas e Ouvidas sobre as Regiões Costeiras) da dinastia Qing (1644-1911)" (GABINENTE DE IMPRENSA DO CONSELHO DE ESTADO DA CHINA, 2016). São esses documentos que legitimam as assertividades chinesas na região, buscando respaldar a Lei sobre o Mar Territorial e Zonas Contíguas de 1992 e dirimir a disputa sobre as ilhas e territórios reivindicados no Mar do Sul.

Naturalmente, os vizinhos possuem suas narrativas e embasamentos históricos, jurídicos e políticos. É o caso das Filipinas, que em junho de 2016 encaminharam - e tiveram aceita - ao Tribunal Permanente de Arbitragem de Haia sua demanda de exploração de recursos no Mar do Sul da China. Segundo o tribunal, não procedem as alegações chinesas acerca das "evidências históricas" de seu controle sobre aquela região. Mesmo que tivesse direitos históricos sobre as águas do Mar do Sul, esses direitos foram extintos pois são incompatíveis com as zonas econômicas exclusivas estabelecidas pela Convenção das Nações Unidas de 1982 sobre o Direito do Mar9.

9 Ver documento oficial da corte disponível em: https://pca-cpa.org/en/news/pca-press-release-the-south-chinasea-arbitration-the-republic-of-the-philippines-v-the-peoples-republic-of-china/ 
Ao que parece, a China já esperava uma resposta negativa, pois, no dia 5 de junho de 2016, no Diálogo China-EUA sobre o Mar do Sul da China entre think tanks chineses e estadunidenses, em Washington D.C, o diplomata chinês veterano Dai Bingguo afirmou que "adjudicação definitiva da arbitragem, que sairá nos próximos dias, equivale a nada mais do que um pedaço de papel” (DAI, 2016).

E mesmo antes da decisão oficial ser publicada, o jornal Global Times já havia escrito um editorial avisando que a reação da China iria depender da provocação das demais partes envolvidas, defendendo que "o povo e governo chineses compartilham dos mesmos interesses e responsabilidades. Nós devemos não apenas salvaguardar a soberania territorial, como também realizar esforços máximos para manter a paz na periferia da China, prolongando as oportunidades estratégicas para a ascensão da China" (GLOBAL TIMES, 2016). Após o veredicto, governo chinês - que havia boicotado as audiências em Haia por não reconhecer a jurisdição do tribunal sobre a disputa - declarou "solenemente que o veredicto é nulo e não possui força vinculativa” (MINISTÉRIO DAS RELAÇÕES EXTERIORES DA CHINA, 2016).

O país asiático reafirma que "em relação às questões territoriais e disputas de delimitação marítima, a China não aceita qualquer meio de solução de disputas por terceiros ou qualquer solução imposta à China" (MINISTÉRIO DAS RELAÇÕES EXTERIORES DA CHINA, 2016). Em outras palavras, prefere realizar as negociações no âmbito das relações bilaterais conforme estabelecido na Declaração de Conduta das Partes no Mar do Sul da China, assinada em 2002 com dez países membros da Associação das Nações do Sudeste Asiático (ASEAN) ${ }^{10}$. Em março de 2016, o vice-ministro de Relações Exteriores da China, Liu Zhenmin, reafirmou tal posição ao declarar que "alguns países gostam de trazer à tona a questão do Mar do Sul da China nos fóruns multilaterais. O propósito verdadeiro deles não é resolver o problema, mas jogar com ele. Isto fez com que a questão do Mar do Sul da China se torne suscetível à exploração externa” (LIU, 2016).

O Livro Branco, publicado em janeiro de 2017, intitulado Sobre a Política Chinesa na área de Cooperação de Segurança na Ásia-Pacífico ${ }^{11}$, revela em detalhes as posições do governo chinês sobre o tema. O texto, através do discurso padrão do governo chinês, ilustra os aspectos positivos das cooperações regionais realizadas

10 Ver íntegra do documento da ASEAN no site oficial, disponível em: http://asean.org/?static_post = declarationon-the-conduct-of-parties-in-the-south-china-sea-2

11 Ver íntegra do documento oficial do governo da RPC, disponível em: http://news.xinhuanet.com/english/ china/2017-01/11/c_135973695.htm 
até agora no assunto. No entanto, o real significado desse documento é estabelecer o quadro teórico para a consolidação da China enquanto uma potência regional, cujo principal obstáculo é a tendência dos países pequenos em procurar alianças com as grandes potências para contrabalancear a ascensão chinesa, trazendo atores extrarregionais para a equação.

No tocante à questão do Mar do Sul, por muito tempo a China foi acusada de buscar a resolução das disputas em espaços bilaterais. Em 2014, o ministro de Relações Exteriores Wang Yi apresentou a ideia da "dupla abordagem”, sinalizando que a China aceitaria lidar com as disputas sobre o Mar do Sul na ASEAN, um espaço multilateral ${ }^{12}$. A aceitação chinesa da regionalização da questão pressupõe o impedimento da internacionalização da contenda com a participação de atores extrarregionais, leia-se a superpotência (EUA), com sua enorme capacidade de influenciar o quadro de forças na região, fomentando a escalada de violência e a desestabilização dos países envolvidos na questão.

\section{Vietnã entre gigantes}

Do ponto de vista teórico, existem duas perspectivas de análise para interpretar as dinâmicas das relações sino-vietnamitas. A primeira assume a primazia de fatores históricos sedimentados no longo prazo que interligam esses dois países asiáticos. O Vietnã assimilou diversos elementos da cultura chinesa por aproximadamente dez séculos (de 3 a.C até 10 d.C), período onde esteve condicionado ao domínio chinês. Essa fase de dominação é interpretada como um momento de fraqueza que somente é superado com a expulsão dos chineses, fato celebrado na historiografia vietnamita (SHARROCK; LIEN, 2014).

A segunda assume a posição geográfica, os conflitos ideológicos e a dinâmica geopolítica. Durante o século XX, o Vietnã e a China, apesar de comungarem de regimes políticos semelhantes, apresentaram diversas contradições, em especial devido à correlação de forças entre a União Soviética e os Estados Unidos. Como aponta Ang Cheng Guan (1998), as duas perspectivas não são excludentes, ao contrário, história e geopolítica são variáveis importantes nas relações sino-vietnamitas. 
As relações entre China e Vietnã têm sido marcadas por cooperação e competição. Durante grande parte da guerra de agressão imperialista contra o Vietnã, ocorrida entre 1 de novembro de 1955 até a queda de Saigon em 30 de abril de 1975, a China proveu um apoio considerável ao país vizinho. No entanto, ao longo da década de 1970, as relações entre os dois países asiáticos começaram a deteriorar-se rapidamente. Por um lado, a adesão do Vietnã ao mecanismo de integração econômica dos países socialistas, o Comecon (Council for Mutual Economic Assistance) e a assinatura de um tratado de cooperação e amizade com a União Soviética, ambos em 1978, irritaram profundamente os chineses. Por outro, a reaproximação chinesa com os Estados Unidos e a posterior normalização das relações sino-estadunidenses em 1979 tampouco agradaram os vietnamitas. No ano de 1978, os chineses cortaram o envio de recursos ao Vietnã. Em um contexto histórico onde o racha sino-soviético dividia o bloco comunista em esferas de influência, as tensões entre os dois estados comunistas acabaram culminando em um conflito armado. Por um lado, os chineses apoiaram as provocações do regime antivietnamita de Pol Pot do Camboja na fronteira entre os dois países. Enquanto isso, como já mencionamos parcialmente, o Vietnã assinava acordos com Laos e a arquirrival chinesa, a URSS, em 1977. As rusgas regionais culminaram na guerra do Vietnã contra Camboja e China. Por outro lado, na década de 1980, as reformas da China serviram de inspiração para a política Doi Moi, ou "renovação", cujo objetivo foi seguir numa linha próxima ao socialismo de mercado chinês (VISENTINI, 2012, p. 156-60). Isto é, não há como subestimar as vicissitudes geopolíticas que permearam as relações sino-vietnamitas no século XX (QIANG 2005).

Após o colapso do campo soviético, a China tornou-se central para preservar as heranças do campo socialista. Isso fez com que muitos dos países socialistas reminiscentes adotassem políticas inspiradas no caminho chinês. No entanto, na perspectiva do Vietnã, a ascensão chinesa como potência econômica em busca de hegemonia regional gera profundas contradições, dadas suas capacidades tecnológicas, financeiras e comerciais completamente assimétricas diante de seus vizinhos do Sudeste Asiático. No Livro Branco intitulado O desenvolvimento pacífico da China, publicado em 2011, o governo chinês detalha seus interesses fundamentais, nomeadamente soberania estatal, segurança nacional, integridade territorial, reunificação nacional, manutenção do sistema político estabelecido pela constituição e salvaguardar o desenvolvimento sustentável econômico e social ${ }^{13}$. 
Consequentemente, as recentes disputas da China no Mar do Sul assumem um caráter estratégico, pois tratam-se de questões de soberania estatal, segurança nacional e integridade territorial. Disputa na qual o Vietnã é uma das partes interessadas.

Já a estratégia do governo do Vietnã tem incluído aproximar-se dos EUA, tanto para fazer um contrapeso à hegemonia regional chinesa quanto para ampliar sua inserção internacional. Não é novidade na história contemporânea do Vietnã a capacidade de enfrentar desafios. Como destaca Visentini (2012, p. 163):

O Vietnã, o Estado pivô da Indochina, oito décadas após sua força política dirigente haver iniciado a resistência ao fascismo, sete após triunfar sobre os japoneses, seis depois de expulsar os franceses e três após ter derrotado os EUA e ter impedido a invasão chinesa, quase duas depois de perder o apoio da potência protetora soviética e vê-la desaparecer, o país enfrenta satisfatoriamente os desafios da globalização e mantém seu regime socialista (de mercado).

É isso que torna a tomada de posição sinuosa, assim como a disputa entre o Vietnã e China extremamente sensitiva, visto que, em um plano, ambos os países comungam do mesmo sistema e ideologia e, em outro, apresentam profundas contradições oriundas de processos históricos e das conflitantes aspirações regionais de ambos os países. Antes mesmo da guerra sino-vietnamita de 1979 eclodir, em 1974 ocorreu a batalha das Ilhas Paracel, uma pequena escaramuça entre as forças chinesas e vietnamitas pelo controle da área, onde o país de Ho Chi Minh sofreu perdas consideráveis. Durante a década de 1980, as tensões fronteiriças estiveram em alta, com acusações de sabotagem vindas principalmente de Hanói. As tensões com a China somente diminuíram na década de 1990, quando o crescimento chinês apareceu como uma oportunidade, em um momento onde a União Soviética se esfacelava e os Estados Unidos mantinham seu embargo contra o país. Desde então, pelo menos no plano institucional, a China e o Vietnã têm mantido um relacionamento estável e amigável, conforme atesta a assinatura de um joint communiqué entre os dois países, por ocasião da visita oficial do secretário-geral do Partido Comunista do Vietnã, Nguyen Phu Trong, à China, entre os dias $12 \mathrm{e}$ 15 de janeiro de 2017.

Por isso, a questão do Mar do Sul é uma disputa quase emocional, onde a resolução do conflito "depende da disponibilidade de cada país em abandonar seus planos e ambições, que estão intimamente ligados à identidade nacional, patrimônio cultural, crescimento econômico e status internacional" 
(CÁCERES, 2014, p. 125). Pois, embora a China se projete como potência mundial, o Vietnã cria cacife para ser o novo tigre asiático.

A questão do Mar do Sul da China tem sido um teste para a dinâmica política e para a integração regional. Nesse sentido, a Declaração Sobre a Conduta das Parte no Mar do Sul da China ${ }^{14}$, de 2002, é ilustrativo da complexidade dos litígios. A declaração pontua que os Estados-membros da ASEAN e o Governo da República Popular da China buscam promover a cooperação, a prosperidade e a confiança mútua; garantir os propósitos e princípios da Carta das Nações Unidas, a Convenção de 1982 das Nações Unidas sobre o Direito do Mar, o Tratado de Amizade e Cooperação no Sudeste Asiático, os Cinco Princípios de Coexistência Pacífica, e outros princípios do direito internacional; permitir a liberdade de navegação e sobrevoo acima do Mar do Sul da China; resolver suas disputas territoriais e jurisdicionais por meios pacíficos, sem recorrer à ameaça ou ao uso da força; promover a proteção do ambiente marinho; combater o crime transnacional, incluindo mas não limitado ao tráfico de drogas ilícitas, a pirataria e assaltos à mão armada no mar, e o tráfico ilegal de armas; dentre outros. Embora não seja um documento capaz de dirimir os conflitos com regras detalhadas, trata-se de um primeiro parâmetro para iniciar uma diplomacia multilateral para resolver o problema.

Um dos efeitos da dinâmica regional de poder e seus conflitos, entre eles os do Mar do Sul da China, tem sido a reaproximação entre Vietnã e EUA. O Vietnã busca uma autonomia em meio ao convívio com dois gigantes: China e EUA. Não quer nem ser um membro submisso de uma eventual reconstituição do sistema sinocêntrico, tampouco se tornar um aliado incondicional do seu maior algoz do processo de independência e unificação do país, os EUA. Com efeito, a diplomacia vietnamita busca uma inserção regional e internacional que lhe confira autonomia e capacidade de negociação, sobretudo no caso dos litígios territoriais.

Conhecedores das relações sino-vietnamitas, os EUA suspenderam o embargo de armas ao Vietnã em maio de $2016^{15}$ e buscam fortalecer as relações bilaterais. Dos 165 U\$ bilhões exportados pelo Vietnã, $18 \%$ foi para os EUA e $11 \%$ para a China - primeiro e segundo destinos. Já as importações, dos 159 U\$ bilhões, $39 \%$ é oriunda da China e 3,9\% dos EUA - primeiro e sétimo fornecedores ${ }^{16}$.

14 Ver detalhes da declaração disponível no site da ASEAN: http://asean.org/?static_post=declaration-on-theconduct-of-parties-in-the-south-china-sea-2

15 El País disponível em: http://brasil.elpais.com/brasil/2016/05/23/internacional/1463986128_113820.html

16 Dados oficiais disponível em: http://atlas.media.mit.edu/en/profile/country/vnm/ 
A conclusão é evidente: a China é o maior parceiro comercial, mas é com os EUA que o Vietnã tem expressivo superávit (os gráficos 1 e 2 abaixo ilustram a evolução econômica e comercial do Vietnã).

Gráfico 1 - Evolução do Produto Interno Bruto do Vietnã - 2005-2015 (U\$ bi).

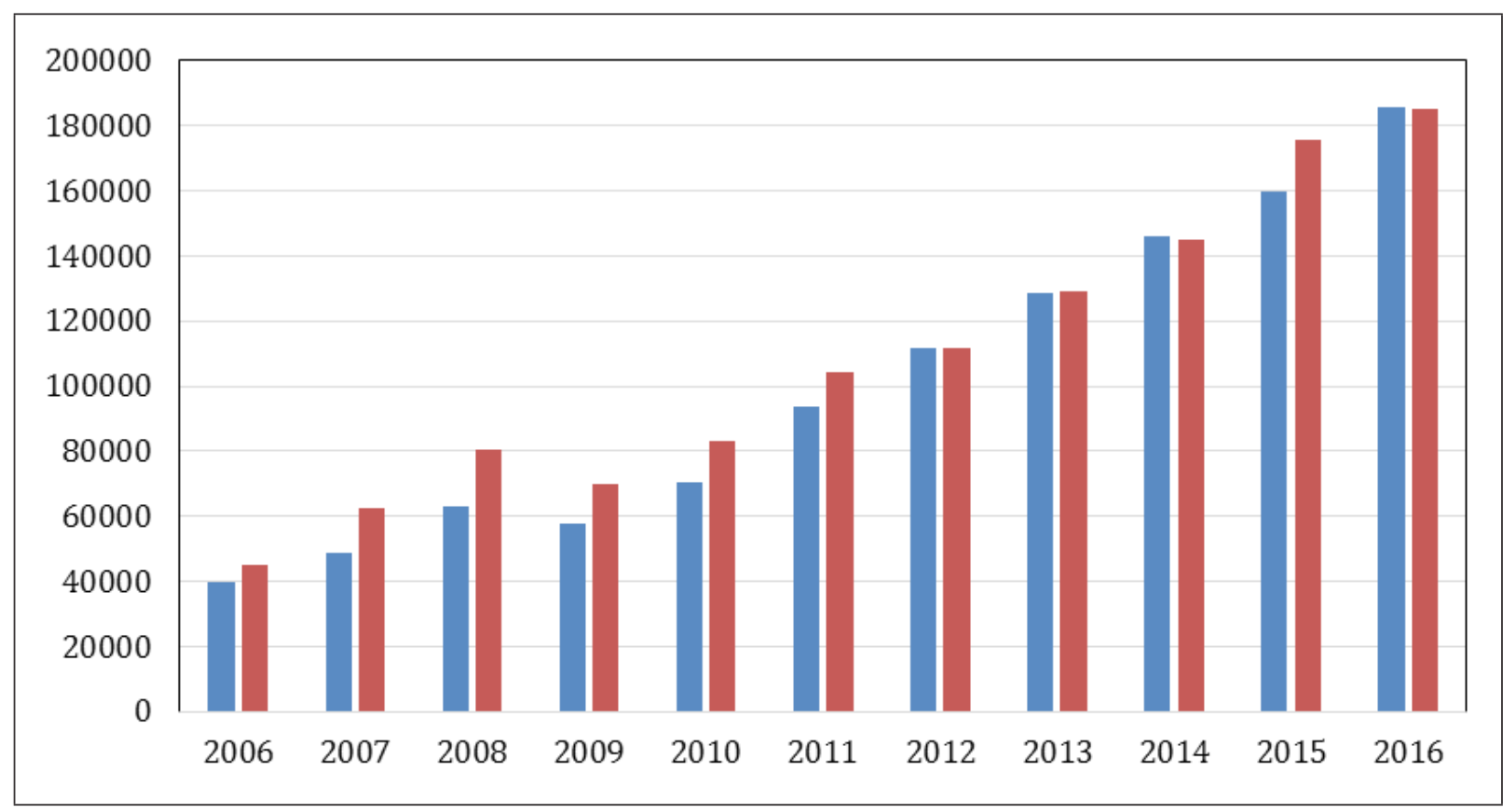

Fonte: IMF, 2017. Dados consultados em 20/07/2017.

Gráfico 2 - Evolução do Fluxo Comercial do Vietnã - 2006-2016 (U\$ mil).

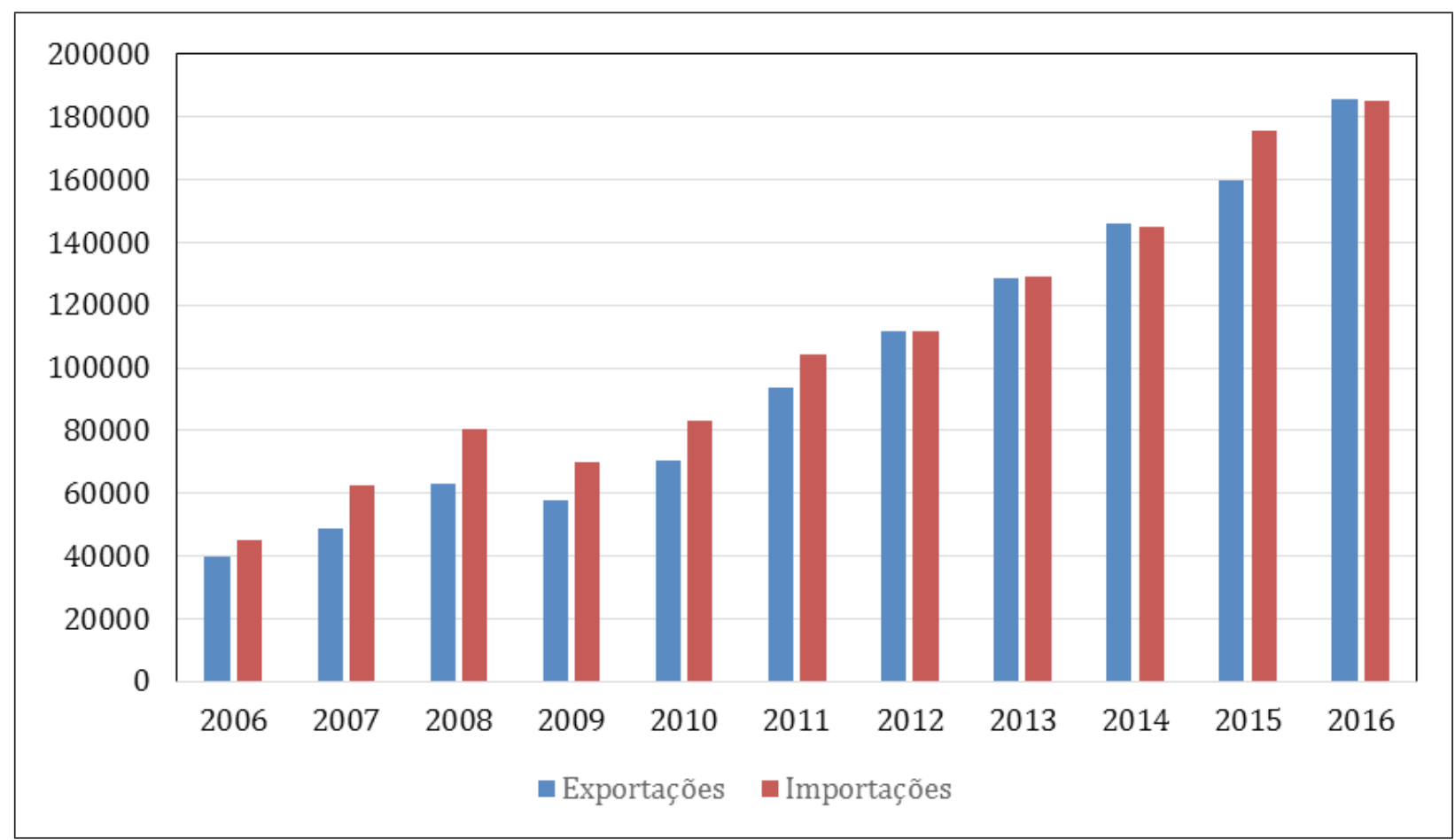

Fonte: IMF, 2017. Dados consultados em 20/07/2017. 
A aproximação do Vietnã com os EUA tem sido evidente e com propósitos bem declarados. De um lado, Harold (2016), do importante think tank estadunidense Rand Corporation, sinaliza claramente que há interesses de contribuir para o rebalanceamento da região, integrando o Vietnã ao Acordo Transpacífico (TransPacific Partnership - TPP) e fortalecendo suas capacidades militares para fazer frente à assertividade chinesa no Mar do Sul da China. Se Obama atuou para suspender ${ }^{17}$, em maio de 2016, o embargo à venda de armas para o Vietnã, decretado em 1975, a eleição de Trump e a retirada dos EUA do TPP colocam novas variáveis na dinâmica regional. Por outro, o Vietnã busca assegurar seus interesses territoriais tendo de lidar não somente com os vizinhos, mas também com uma grande potência (China) e a outra superpotência (EUA) com atuação regional.

Enfim, China e Vietnã estão diante de uma problemática territorial e securitária delicada com potencial de arrastar os países para situações cujo custo superaria em muito os eventuais ganhos. Nesse sentido, têm ocorrido, na esfera diplomática e institucional, tentativas de uma reaproximação amistosa, com promessas de entendimento mútuo e resolução de disputas por formas pacíficas. Em 2011, ambos assinaram um acordo sobre as diretrizes básicas para a resolução de disputas marítimas. O documento declara que "nas negociações sobre questões relacionadas com o mar, os dois lados devem respeitar os acordos e o entendimento comum alcançado por seus líderes de alto nível e aderir aos princípios e no espírito da 'Declaração Sobre a Conduta das Parte no Mar do Sul da China.'”18. Em 2013, durante uma visita oficial ao Vietnã, o premier chinês Li Keqiang disse que "como vizinhos e parceiros, a China e o Vietnã são importantes um para o outro e ambos os países são economicamente complementares com amplo espaço para cooperação prática" ${ }^{19}$. Na época, a mídia vietnamita reportou que os dois lados se comprometeriam a utilizar todos os mecanismos governamentais para resolver disputas territoriais, concordando em estabelecer um grupo de trabalho sobre cooperação marítima dentro dessa perspectiva ${ }^{20}$. Em 2015, o presidente da China, Xi Jinping, em visita ao Vietnã, após encontrar com diversos membros do alto escalão do estado e do Partido Comunista do Vietnã (PCV) na assembleia nacional, declarou que os dois países, ambos aderentes à liderança de partidos

\footnotetext{
17 Ver detalhes no site do Departamento de Defesa dos EUA disponível em: https://www.defense.gov/News/ Article/Article/779762/lifting-embargo-allows-closer-us-vietnam-cooperation-obama-carter-say/

18 Ver http://www.mofa.gov.vn/en/nr040807104143/ns111013131225

19 Ver http://www.china.org.cn/china/2013-06/20/content_29184811.htm

20 Ver http://english.vietnamnet.vn/fms/government/86738/chinese-premier-li-keqiang-visits-vietnam.html
} 
comunistas, firmes no caminho socialista e no aprofundamento compreensivo da reforma, precisam colocar suas relações bilaterais em um patamar de destaque e se esforçar para cimentar uma parceria estratégica ${ }^{21}$. Em janeiro de 2017, em visita do secretário-geral do PCV, Nguyen Phu Trong, a China demonstrou a importância dada à reaproximação entre os dois países comunistas através da assinatura de um novo comunicado conjunto, onde as partes reafirmam os compromissos estabelecidos nos últimos anos²2.

No âmbito social há um profundo descontentamento com a China entre os vietnamitas. As tensões escalaram em 2014, quando a China resolveu instalar uma plataforma de petróleo em área disputada pelos dois países. Houve uma forte reação do povo vietnamita e uma onda de protestos irrompeu, com depredação de instalações físicas de empresas chinesas no Vietnã e ataque aos cidadãos chineses vivendo no país ${ }^{23}$. A imagem da China entre os vietnamitas tem assumido cada vez mais um aspecto negativo. Em 2015, uma pesquisa realizada pelo Pew Research Center em 40 países, com 45.435 respondentes, quando perguntados quais são as maiores ameaças no mundo atualmente, $60 \%$ dos respondentes vietnamitas optaram pelas disputas territoriais com a China. O Vietnã foi o único país do mundo onde essa opção ganhou ${ }^{24}$.

Portanto, as relações sino-vietnamitas sempre foram marcadas pelas vicissitudes geopolíticas e por seu passado, passando ora por fases de intensa cooperação e ora por fases de grande animosidade. Assim, as disputas em torno do Mar do Sul da China também têm influência na política interna e nos padrões de amizade sino-vietnamitas. Em uma carta publicada pelo Journal of Democracy — periódico acadêmico de cunho liberal - , datada de 28 de julho de 2014, 61 membros do Partido Comunista do Vietnã (PCV) - em desacordo com a linha central do Partido - denunciam que:

Por muitos anos, o Partido Comunista do Vietnã liderou a nação na direção errada de construir o socialismo no estilo soviético, baseado no chamado marxismo-leninismo. A política Doi Moi que começou há trinta anos tentou

21 Ver http://news.xinhuanet.com/english/2015-11/06/c_134791569.htm

22 Ver http://hanoitimes.com.vn/news/2017/01/81E0ADEB/full-text-of-vietnam-china-joint-communique/

23 Desde então, diversos incidentes vêm ocorrendo: restaurantes no Vietnã se recusando a atender clientes chineses e um oficial de imigração do Vietnã supostamente escreveu "fuck you" no passaporte de uma chinesa, em cima do mapa onde retrata os territórios disputados como parte da China. Ver informação complementar: http://world.huanqiu.com/exclusive/2016-08/9249497.html

24 Ver: http://www.pewglobal.org/2015/07/14/climate-change-seen-as-top-global-threat/ 
corrigir os erros na política econômica, mas não foi radical o suficiente pois manteve o regime totalitário que restringe a liberdade e a democracia e mantém o nosso povo dividido. ${ }^{25}$

Além da conclamação pelo fim da experiência socialista vietnamita, o documento é dedicado a criticar a postura expansionista chinesa e parte da liderança simpática à China. Há também uma denúncia pela publicação dos detalhes do Acordo de Chengdu, de 1990, onde supostamente a liderança vietnamita fez fortes concessões à RPC. O surgimento desse documento veio no bojo das turbulências enfrentadas devido à instalação de uma plataforma de petróleo chinesa em uma área disputada pelos dois países. A carta revela a existência concreta desses grupos de interesse que terminaram por se manifestar na disputa pelo poder no $12^{\circ}$ Congresso do Partido Comunista do Vietnã, realizado em 2016. De um lado, o primeiro-ministro Nguyen Tan Dung, considerado como grande proponente da economia de mercado dentro do PCV, ganhou notoriedade durante a crise da plataforma de petróleo chinesa em 2014 ao aumentar o tom contra a China ${ }^{26}$. É um dos grandes defensores da aproximação do Vietnã com os Estados Unidos. Do outro lado, o secretário-geral do PCV Nguyen Phu Trong, educado na União Soviética, é considerado um dos grandes ideólogos do partido, busca realinhar a organização com seus princípios fundadores e enxerga na China um aliado ideológico e estratégico. (LE, 2017, p. 78-83).

A contenda deve ser interpretada para além da disputa pelo cargo de secretáriogeral vencida por Nguyen Phu Trong, reeleito para o cargo após uma concessão do partido em estender seus direitos políticos para além da idade máxima para a aposentadoria compulsória. A diferença entre os dois candidatos está no que Tuong Vu, cientista político na Universidade de Oregon, em entrevista ao New York Times, ressaltou: "todas as facções concordam com a necessidade de investimentos e comércio, mas a facção de Trong resistirá a quaisquer concessões, enquanto a facção de Dung tentaria assinalar reformas para manter o dinheiro entrando" 27. Para além dessas diferenças, a disputa política influi na inserção internacional do Vietnã, mais ou menos alinhada com China e/ou Estados Unidos e na direção dos conflitos no Mar do Sul.

\footnotetext{
25 Ver: http://journalofdemocracy.org/sites/default/files/custom_search/Letter \%20from \%2061 \% 20Vietnamese \% 20 Party \% 20members.pdf

26 Ver: https://www.nytimes.com/2014/05/12/world/asia/vietnam.html

27 Ver: https://www.nytimes.com/2016/01/28/world/asia/vietnam-communist-party-nguyen-phu-trong.html?_r=0
} 
Em suma, no curto prazo pelo menos, a política externa do Vietnã continua sendo marcada pela independência, autossuficiência e busca por diversificação e multilateralização das relações internacionais. A posição geográfica e a história do Vietnã empurram o país nessa direção. No entanto, a busca pela reaproximação com os EUA, para contrabalancear a assertividade da China, não esvazia o conteúdo nacional e seus compromissos ideológicos. A pareceria com a China tampouco tem como objetivo uma aliança cega baseada em concessões ilimitadas. O desafio está posto.

\section{Para além das disputas sino-vietnamitas no Mar do Sul}

É possível que os EUA tenham influenciado a demanda filipina junto ao Tribunal de Haia para fomentar o litígio e a consequente construção de alianças antichinesas na região. Não se deve esquecer os laços que os unem, dado que os EUA concederam a independência das Filipinas condicionada ao estabelecimento de suas bases militares (LOSURDO, 2016, p. 247). Mas, de acordo com Viktor Sumsky ${ }^{28}$, diretor do Centro da ASEAN na Universidade de Relações Internacionais de Moscou, o encaminhamento ao tribunal tende a produzir um resultado contraproducente e potencializar o conflito, uma vez que o direito internacional existe para resolver pacificamente as situações de conflito, sobretudo porque a iniciação do processo de arbitragem exige a concordância de ambos os lados.

Os EUA, em conjunto com seus aliados, anteciparam-se em criticar a China pela decisão de não respeitar a decisão da corte. Cabe destacar que os próprios Estados Unidos, em 1986, ignoraram uma arbitragem do Tribunal de Haia, que declarou suas atividades na Nicarágua ilegais. Além disso, não consta que os membros permanentes do Conselho de Segurança da ONU sejam notórios aplicadores das normas internacionais que eles julguem que possam infringir suas soberanias e interesses nacionais. A decisão unilateral dos EUA de invadirem o Iraque e a anexação da Crimeia pela Rússia são dois exemplos dessa tendência. Não obstante a postura estadunidense, fica a dúvida acerca do comportamento que a China irá adotar para dirimir esse conflito sem replicar as práticas das potências tradicionais — inclusive em razão da importância logística do Mar do Sul (Figura 1).

28 Em declaração dada à Sputnik Brasil, disponível em: http://br.sputniknews.com/mundo/20160708/5511304/ haia-china-filipinas.html 
Figura 1 - As redes de transporte terrestres e marítimas ${ }^{29}$.

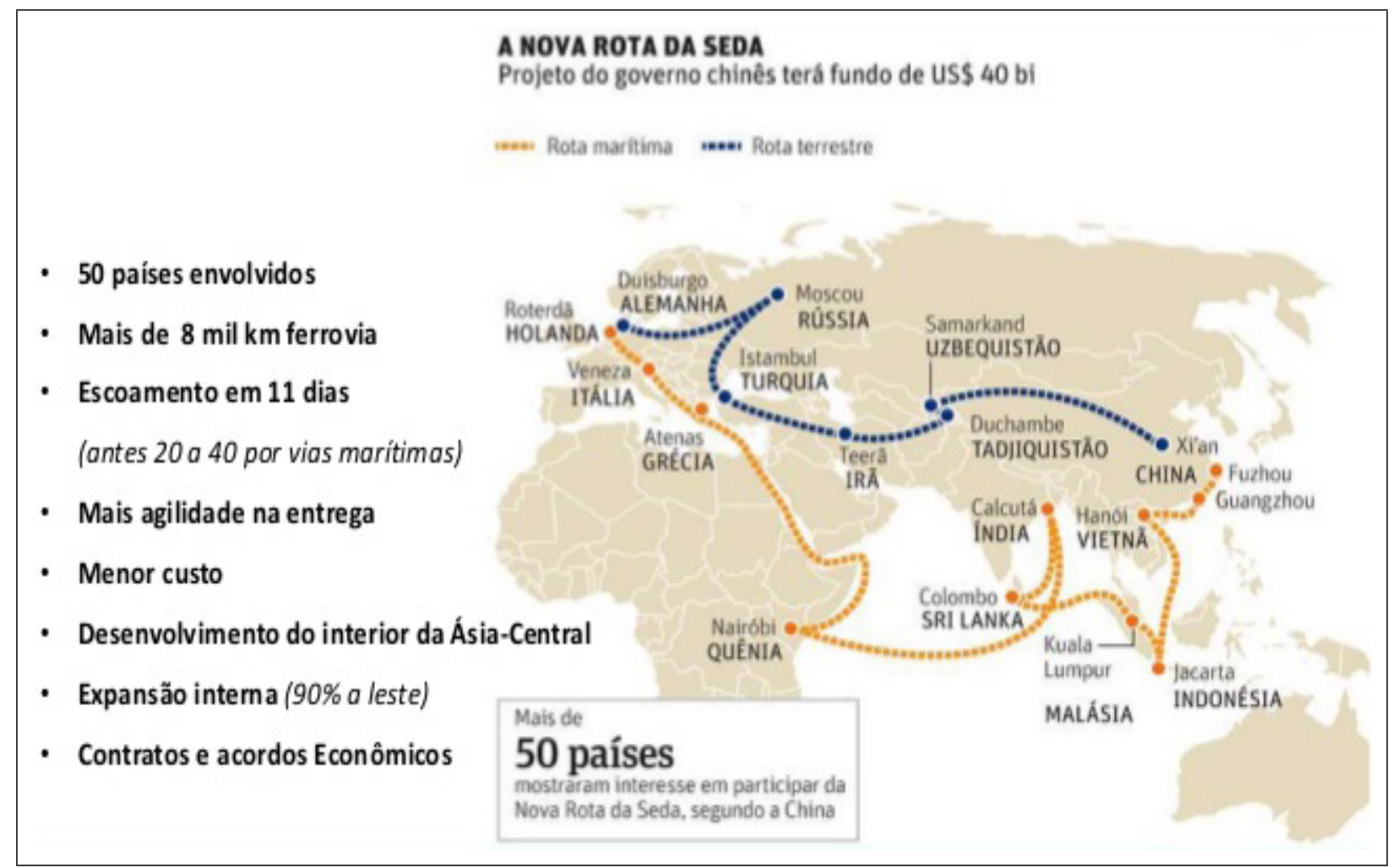

Fonte: FSP. Disponível em: http://www1.folha.uol.com.br/mercado/2015/10/1695869-politica-externa-chinesa-buscacriar-uma-nova-estrada-da-seda.shtml.

Embora haja legítimas disputas territoriais por essa região, é importante reconhecer que as raízes são mais profundas. A começar pelo fato de que os EUA não são signatários da Convenção das Nações Unidas sobre o Direito do Mar documento no âmbito do direito internacional que dispõe sobre os conceitos relacionados ao mar territorial - e tampouco fazem parte da região. Ou, como destaca Losurdo (2016, p. 238), os EUA são reincidentes em desconsiderar os organismos internacionais, como foi o caso da condenação em 1986 do Tribunal de Haia pelas agressões contra a Nicarágua sandinista ou mesmo a rejeição à Corte Penal Internacional.

Nesse sentido, para os interesses estratégicos dos EUA, as disputas no Mar do Sul da China se prestam a muitos objetivos regionais. Primeiro, fortalecer a narrativa da "ameaça chinesa", a partir de seu militarismo e expansionismo. Segundo, ampliar sua presença militar na região como forma de resguardar seus parceiros. Terceiro, fomentar padrões de inimizade para fragilizar a liderança da China na região. Quarto, gerar dissensos para fragilizar as iniciativas de integração

29 Há outras versões desse mapa Disponível em: Maps of China - http://english.igsnrr.cas.cn/eocg/moc/. O IGSNRR é o Instituto de Geografia e Ciências Naturais diretamente ligado à Academia Chinesa de Ciências. 
regionais conduzidas pelos chineses, tanto relacionadas à ASEAN quanto à Rota da Seda Marítima. Quinto, tentar engolfar a China num conflito regional que seria o "seu Vietnã". Cabe destacar que os EUA usam o controle sobre o Estreito de Malaca, o cerco militar e a chantagem nuclear como uma ameaça permanente à China (KAPLAN, 2015).

A ascensão da China, até o presente momento, foi um processo pacífico e relativamente suave, onde a ordem internacional - não sem atritos - abriu espaço para acomodar a nova potência econômica. O país asiático foi sagaz ao buscar oportunidades em regiões esquecidas pelo eixo euro-estadunidense. No entanto, à medida que a influência e o poderio chinês crescem, também crescem suas responsabilidades diplomáticas internacionais. A estratégia adotada de não intervenção e neutralidade, que garantiu poucos desgastes para a China, já não comporta mais os desafios e barreiras do quadro atual enfrentado pela crescente assertividade do país asiático.

É evidente que os EUA vão explorar os conflitos na Ásia-Pacífico para criar entraves à liderança chinesa. Kissinger foi explicito, por exemplo, em indicar que o Japão deve redefinir seu papel na ordem mundial e se tornar um "país normal" (KISSINGER, 2011, p. 193). Para os EUA, não interessa apenas que o Japão seja um aliado militarmente capaz e assertivo, mas também justificar a forte presença dos EUA na península coreana (face à Coreia do Norte) e no Mar do Sul. Não é por acaso que a presença militar dos EUA, com exercícios e manobras, tem ocorrido com regularidade. Por exemplo, em junho de 2016, os dois maiores porta-aviões estadunidenses, os USS John C. Stennis e USS Ronald Reagan, participaram de exercícios militares no Mar das Filipinas, com mais de 12 mil marinheiros, 140 aeronaves e 6 navios de guerra ${ }^{30}$. A desproporção de forças combinado ao evidente e histórico "poder de polícia internacional" autoconferido aos EUA são razões suficientes para as preocupações chinesas e para o risco de uma escalada militar.

O jornalista e especialista na questão, Bill Hayton, assinalou corretamente que dois imperativos estratégicos e diversos interesses regionais colidem no Mar do Sul da China. A disputa é perigosa pois cristaliza, de certa forma, a imagem que as duas nações conferem a si próprias. De um lado, está a China que, através do Partido Comunista da China, busca o rejuvenescimento da nação chinesa e a recuperação dos territórios e dignidade perdidos no chamado Século das Humilhações, de outro, estão os Estados Unidos e seu destino manifesto de líder

30 Ver informações na Sputnik Brasil, disponível em: http://br.sputniknews.com/mundo/20160622/5228728/ rivalidade-pequim-washington.html 
global, protetor do "mundo livre" e guardião da ordem internacional. Hayton sustenta que o Mar do Sul da China é o primeiro lugar onde as normas e regras desse sistema internacional estão sendo desafiadas pela China, pois se os EUA perdem o controle sobre as navegações pela região, perderão sua predominância global e se tornarão apenas mais uma potência. Caso isso ocorra, o "choque seria profundo e as consequências para a identidade, prosperidade e segurança estadunidenses, devastadoras" (HAYTON, 2014, p. 208).

Em suma, essas demonstrações de força revelam que os EUA estão cada vez menos dispostos a assistir à ascensão chinesa. Com efeito, a questão do Mar do Sul da China é mais uma das formas de tentar contê-la, tal como foi feito com a URSS durante a Guerra Fria. A isso se somam os intentos estadunidenses para desagregar a China através de movimentos separatistas no Tibete e no Xingjian (BANDEIRA, 2013, p. 119). Há inclusive de se considerar o paralelo existente entre o conflito da Ucrânia e os litígios no Mar do Sul. Em ambos os casos, tem se tentado engolfar as potências desafiantes - China e Rússia - em conflitos regionais. A partir disso, é possível "vilanizar" os países em questão e criar enormes desafios às suas iniciativas internacionais. É inegável, por fim, que a questão do Mar do Sul certamente será um marco divisor na atuação internacional da China.

\section{Conclusões}

O litígio no Mar do Sul da China é, sem dúvida, um dos temas mais importantes das relações internacionais contemporâneas. Trata-se de uma questão complexa pois envolve i) diversos contendores regionais e ainda o protagonismo da superpotência (EUA) extrarregional; ii) a superposição de dinâmicas de integração com o recrudescimento da competição; e iii) entrelaçamento de padrões de relacionamento histórico (sinocêntrico) com a sobreposição dos conceitos centrais ao moderno sistema de governança mundial (HADDICK, 2014).

A política estadunidense é de contenção da China, se possível eliminando as peças (aliados) do seu oponente, quiçá numa vitória total. Ao invés do xadrez, a China prefere uma política de campanha prolongada, movendo-se pelos espaços "vazios", mitigando o potencial estratégico do oponente de maneira flexível, onde os elementos políticos e psicológicos são tão importantes como os militares (Tzu). O conflito no Mar do Sul tem claramente elementos dessa cosmologia, sem deixar de ter agregado novas concepções e meios. 
A China, como potência da região, tem percorrido o caminho sinuoso de, a um só tempo, preservar sua segurança e liderar os processos de integração regionais, mas sem replicar um padrão expansionista que legitime a estratégia estadunidense. A China busca a recriação do sistema sinocêntrico a partir de iniciativas para liderar a integração regional (ASEAN + 6 e Organização para a Cooperação de Xangai), amarrado na Nova Rota da Seda Continental e Marítima (One Belt, One Road) e no Banco Asiático de Investimento em Infraestrutura. Não resta dúvidas que a Iniciativa OBOR provoca novas demandas e desafios geopolíticos e geoeconômicos para a China, ao passo que atesta a necessidade de compatibilizar as relações “win-win” com a atuação assertiva de sua diplomacia (PAUTASSO, UNGARETTI, 2017). Se houver sentido na hipótese de que a Nova Rota da Seda é um projeto chinês de globalização, esse só será viável com a viabilização da integração regional e, com efeito, dependeria de um padrão de relacionamento estável na região e o equacionamento - ou pelo menos o gerenciamento - dos litígios no Mar do Sul da China.

Mas o Vietnã tem uma estratégia de hedging baseada no reforço e diversificação das suas relações externas diante da assertividade regional da China (TRAN; VIEIRA; FERREIRA-PEREIRA, 2013). Aliás, os países da região buscam a um só tempo fazer parte dessa janela de oportunidade ligada à Iniciativa OBOR e preservar a autonomia diante do gigante asiático. Para tanto, mantêm equilíbrio delicado entre China e EUA, numa nítida política de barganha. Resta saber se os choques de objetivos, de temporalidades e de cosmologias poderão ser administrados.

\section{Referências}

BANDEIRA, Luiz. Segunda Guerra Fria. Rio de Janeiro: Civilização Brasileira, 2013. BUZAN, Barry; HANSEN, Lene. A evolução dos Estudos de Segurança Internacional. São Paulo: UNESP, 2012.

BUSZYNSKI, Leszek. The South China Sea: Oil, Maritime Claims, and U.S.-China Strategic Rivalry. The Washington Quarterly. Vol. 35, n 2, 2012, pp. 139-156. Disponível em: http://www.tandfonline.com/doi/abs/10.1080/0163660X.2012.666495.

CÁCERES, Sigfrido Burgos. China's Strategic Interests in the South China Sea: Power and resources. New York: Routledge, 2014.

DAI, Bingguo. Speech by Dai Bingguo at China-US Dialogue on South China Sea Between Chinese and US Think Tanks. Ministry of Foreign Affairs of the People's Republic of China. 07 05, 2016. http://www.fmprc.gov.cn/mfa_eng/zxxx_662805/t1377747.shtml (accessed 07 15, 2016). 
DENG, Xiaoping. Selected Works of Deng Xiaoping Volume III. Vol. III. III vols. Beijing: Foreign Language Press, 1994.

FRAVEL, M. Taylor. China's Strategy in the South China Sea. Contemporary Southeast Asia, vol. 33, no. 3, 2011,p. 292-319. Disponível em: https://taylorfravel.com/documents/ research/fravel.2011.CSA.china.strategy.scs.pdf.

GABINETE DE IMPRENSA DO CONSELHO DE ESTADO DA CHINA. A China persiste em resolver através de negociações as disputas com as Filipinas no Mar do Sul da China. Rádio Internacional da China. 07 13, 2016. http://portuguese.cri.cn/1721/ 2016/07/13/1s218533.htm (accessed 07 18, 2016).

GILL, Bates. Rising Star: China's New Security Diplomacy. Wahington: Brooking Instituto Press, 2007.

GLOBAL TIMES. China's reaction to arbitration depends on provocation. 07 12, 2016. http://www.globaltimes.cn/content/993655.shtml (accessed 07 15, 2016).

GUAN, Ang Cheng. Vietnam-China Relations since the End of the Cold War. Asian Survey (University of California Press) Vol. 38, no. 12, 1998, p. 1122-1141.

Haddick, Robert. Fire on the Water: China, America, and the Future of the Pacific. New York: Naval Institute Press, 2014.

HAYTON, Bill. The South China Sea: The Struggle for Power in Asia. New Haven: Yale University Press, 2014.

HAROLD, Scott. Why Obama Lifted de Arms Sales Ban on Vietnam? 2016. https://www. rand.org/blog/2016/05/why-has-obama-lifted-the-arms-sales-ban-on-vietnam.html. Acesso 10/03/2017.

IMF. World Economic Outlook. 2017. Disponível em: http://www.imf.org/en/publications/weo. KANG, David. Hierarchy and stability in Asian international relations. In: IKENBERRY, John; MASTANDUNO, Michael. International Relations Theory and the Asia-Pacific. New York: Columbia, 2003, pp. 163-189.

Kaplan, Robert D. Asia's Cauldron: The South China Sea and the End of a Stable Pacific. New York: Random House Trade Paperbacks, 2015.

Kissinger, Henry. Sobre a China. Rio de Janeiro: Objetiva, 2011.

LE, Hong Riep. Living Next to the Giant: The Political Economy of Vietnam's Relations with China Under Doi Moi. Singapore: ISEAS Publishing, 2017.

Li, Jingzhi, and Ping Pu. The Choice of China: Peaceful Development and Construction of a Harmonious World. Beijing: Renmin University Press, 2012.

LI, Xue. 薛力: 南海问题上中美都应有所反思. 共识网. 06 29, 2016. http://www.21ccom. net/html/2016/zlwj_0629/5358.html (accessed 07 19, 2016).

LIU, Zhenmin. China Remains Committed to Peaceful Settlement of Disputes in the South China Sea through Negotiations and Consultations. Ministry of Foreign Affairs of the People's Republic of China. 03 25, 2016. http://www.fmprc.gov.cn/mfa_eng/wjbxw/ t1350776.shtml (accessed 07 18, 2016).

LOSURDO, Domenico. A esquerda Ausente. São Paulo: Anita Garibaldi, 2016. 
MINISTÉRIO DAS RELAÇÕES EXTERIORES DA REPÚBLICA POPULAR DA CHINA. Declaração do Ministério das Relações Exteriores da China sobre o veredicto do Tribunal Arbitral na Arbitragem do Mar do Sul da China. 07 12, 2016. http://portuguese.cri. cn/1721/2016/07/12/1s218493.htm (accessed 07 18, 2016).

MINISTRY OF FOREIGN AFFAIRS OF THE PEOPLE'S REPUBLIC OF CHINA. China's Position Paper on the New Security Concept (July 31, 2002). Ministry of Foreign Affairs of the People's Republic of China. 08 06, 2002. http://www.fmprc.gov.cn/mfa_eng/ wjb_663304/zzjg_663340/gjs_665170/gjzzyhy_665174/2612_665212/2614_665216/ t15319.shtml (accessed 07 17, 2016).

PAUTASSO, Diego; UNGARETTI, Renato. A Nova Rota da Seda e a recriação do sistema sinocêntrico. Estudos Internacionais. Vol. 4, n ${ }^{\circ}$ 3, 2016, p. 25-44. Disponível em: http://periodicos.pucminas.br/index.php/estudosinternacionais/article/view/13874 PEREIRA, Analúcia D.; MEDEIROS, Klei. O Prelúdio da Cooperação Sul-Sul: da Conferência de Bandung à Conferência de Buenos Aires (1955-1978). I Seminário Internacional de Ciência Política Universidade Federal do Rio Grande do Sul, Porto Alegre, Set. 2015. QIANG, Zhai. China and the Vietnam Wars, 1950-1975. The University of North Carolina Press, Chapel Hil, 2005.

SHARROCK, Peter D.; LIEN, Vu Hong. Descending Dragon, Rising Tiger: A History of Vietnam. London: Reaktion Books, 2014.

SHICUN, Wu, ed. What one needs to know about the South Sea. Beijing: Current Affairs Press, 2015.

TALMON, Stefan; BING, Bingjia. The South China Sea Arbitration: A Chinese Perspective. Oxford: Hart Publishing, 2014.

TRAN, Phuc Thi; VIEIRA, Alena; FERREIRA-PEREIRA, Laura, Vietnam's strategic hedging vis-à-vis China: the roles of the European Union and Russia. Revista Brasileira de Política Internacional. Vol. 56, $\mathrm{n}^{\circ}$. 1, 2013, p. 163-182. Disponível em: http://www. scielo.br/scielo.php?script = sci_arttext\&pid = S0034-73292013000100009

VISENTINI, Paulo. As Relações Diplomáticas da Ásia. Belo Horizonte: Fino Traço, 2012. Zhang, Haiwen, ed. The South China See and its Island. Beijing: China Intercontinental Press, 2014.

ZHENG, Bijian. China's Peaceful Rise: Speeches of Zheng Bijian 1997. Washington: Brookings Institution Press, 2005. 